\title{
DIAGNÓSTICO DAS MANIFESTAÇÕES DA OUVIDORIA DA SECRETARIA DO TRABALHO E DESENVOLVIMENTO SOCIAL DO ESTADO DO CEARÁ (STDS) COM FOCO NA RESOLUBILIDADE ${ }^{1}$
}

\author{
Paulo Henrique de Araújo Lima² \\ Lise Alcântara Castelo ${ }^{3}$
}

\begin{abstract}
Resumo
Por considerar que as Ouvidorias Públicas representam um poderoso instrumento de participação social, por meio do qual se estabelecem as inter-relações dos indivíduos com os agentes institucionais, decidiu-se investigar nesse estudo as demandas e o índice de resolubilidade das manifestações recebidas pela Ouvidoria da Secretaria do Trabalho e Desenvolvimento Social do Estado do Ceará - STDS, no ano de 2015. Essa pesquisa de caráter quantitativo utilizou o Sistema de Ouvidoria (SOU) da Controladoria-Geral do Estado (CGE) para a coleta de dados, a fim de traçar um diagnóstico das manifestações da Ouvidoria da STDS e determinar seu índice de resolubilidade a partir da análise das seguintes categorias: meio de entrada das manifestações; tipo, assunto; e tempo de resposta, com o objetivo de identificar se essa Ouvidoria alcançou um índice satisfatório em relação ao atendimento das manifestações recebidas. Considerou-se como resolubilidade, no âmbito das Ouvidorias Públicas do Estado do Ceará, o atendimento às demandas dentro do prazo estabelecido pelo Decreto $n^{\circ} 30.474 / 2011$. A análise dos dados apontou para um alto índice de resolubilidade das manifestações, o que demonstra o nível de eficiência da Ouvidoria da STDS em relação ao feedback dado ao cidadão. O mapeamento das manifestações revelou, ainda, a necessidade de melhoria nos serviços prestados ao cidadão. Como consequência, os dados servirão como indicadores para a melhoria no tratamento das manifestações recebidas e dos serviços prestados ao cidadão, a fim de aperfeiçoar esse importante instrumento de gestão e participação cidadã.
\end{abstract}

Palavras-chave: Ouvidoria Pública. Participação cidadã. Transparência. Resolubilidade

\section{DOI:10.37814/2594-5068.2018v1.p116-134}

1 Este artigo é parte integrante da pesquisa objeto da monografia Diagnóstico das Manifestações da Ouvidoria da Secretaria do Trabalho e Desenvolvimento Social do Estado do Ceará (STDS), com foco na resolubilidade, apresentada ao Programa de Pós-Graduação em Gestão Pública da Faculdade Metropolitana da Grande Fortaleza (Fametro), para obtenção do grau de Especialista.

2 Especialista em Gestão Social pela Faculdade Metropolitana da Grande Fortaleza. Ouvidor da Secretaria do Trabalho e Desenvolvimento Social (STDS) do Governo do Estado do Ceará. (paulohenrique.lima@stds.ce.gov.br)

3 Professora Orientadora. Mestre em Engenharia da Produção, pela Universidade Federal da Paraíba. Professora do Centro Universitário UNICHRISTUS, Fortaleza. (lise@mpce.mp.br) 


\begin{abstract}
Due to the fact that Public Ombudsman's Offices represent a powerful tool of social participation, by means of which the interrelations between individuals and institutional agents are established, the demands and the resolvability rate of the manifestations received by the Secretariat of Labor and Social Development in the State of Ceará - STDS's Ombudsman's Office, in the year of 2015, are investigated in this study. This quantitative research utilized the Ombudsman's Office System (SOU) of the General Controllership in the State of Ceará (CGE) for the data collection in order to provide a diagnosis of the STDS's Ombudsman's Office manifestations and determine its resolvability rate, starting from the analysis of the following categories: means of entry of the manifestations; type, subject; and answer time, with the objective of identifying if this Ombudsman's Office reached a satisfactory rate with relation to the fulfillment of the manifestations received. It was considered as resolvability, in the scope of Public Ombudsman's Offices in the State of Ceará, the fulfillment of the demands within the deadline established by Decree $n^{\circ} 30.474 / 2011$. The analysis of the data indicated a high resolvability rate of the manifestations, which demonstrates the level of efficiency of STDS's Ombudsman's Office with relation to the feedback given to the citizens. The mapping of the manifestation also revealed the necessity of improvement in the service provided to the citizens. As a consequence, the data will serve as indicators for the improvement in the treatment of the manifestations received and the services provided to the citizens, in order to optimize this important tool of management and citizen participation.
\end{abstract}

Key-words: Public Ombudsman's Office. Citizen participation. Transparency. Resolvability. 


\section{INTRODUÇÃO}

Nas sociedades contemporâneas democráticas, as Ouvidorias Públicas desempenham um papel fundamental na aproximação dos cidadãos com as instituições públicas, pois permitem uma posição ativa e de intervenção da sociedade na estrutura governamental, e possibilitam a participação direta do cidadão na tomada de decisões.

No Brasil, as Ouvidorias Públicas começaram a se destacar a partir da década de 1980, em virtude do processo de abertura democrática e da ampliação dos canais de comunicação entre a sociedade civil e o Estado, antes insuficientes. Assim, novas formas de governança passaram a considerar a cooperação e a participação da sociedade civil na elaboração, execução e controle das políticas públicas, evidenciando o papel das Ouvidorias como canais de comunicação entre a sociedade e o Estado, com vistas ao aperfeiçoamento da prestação de serviços públicos e à legitimação das decisões da Administração Pública.

No Estado do Ceará, as Ouvidorias Públicas estão inseridas no Sistema de Ouvidoria do Estado do Ceará (SOU), uma ferramenta informatizada instituída pelo Decreto no. 30.474/2011 e criada pela Controladoria e Ouvidoria-Geral do Estado (CGE) para facilitar o contato com as diversas Ouvidorias Setoriais da Administração Pública e otimizar o atendimento das manifestações dos cidadãos a elas encaminhadas. A Rede de Ouvidorias do Estado é composta por 66 (sessenta e seis) Ouvidorias Setoriais dos órgãos e entidades do Poder Executivo Estadual, atuando na apuração e resposta das manifestações apresentadas pelo cidadão, com a responsabilidade de receber e encaminhar as manifestações (denúncias, reclamações, elogios, sugestões e pedidos de informação) referentes a procedimentos e ações de agentes, órgãos e entidades do Poder Executivo Estadual.

Cabe destacar que as Ouvidorias Públicas no Brasil passaram a constituir um campo de estudo com um número cada vez maior de pesquisas realizadas com o objetivo de aprofundar o conhecimento sobre seu funcionamento e atuação no âmbito da sociedade brasileira. Muitas dessas pesquisas (LOPES e ANTUNES, 2010; OLIVEIRA e MARCELINO, 2010; MARCELINO, 2010) baseiam-se em corpus coletados a partir dos sistemas implantados pelos órgãos governamentais responsáveis pelo acolhimento das manifestações encaminhadas pelos cidadãos, representando dados reais, colhidos a partir de fontes oficiais, de forma sistemática e organizada.

Considerando a relevância do tema em questão, e por julgar que o conjunto das manifestações constitui um ato fundamental do exercício da cidadania, decidimos investigar nesse estudo quantitativo, baseado em um corpus, as demandas e o índice de resolubilidade das manifestações encaminhadas à Secretaria do Trabalho e Desenvolvimento Social (STDS) do Estado do Ceará no ano de 2015, já que um diagnóstico sobre essas demandas permite a identificação do meio de entrada dessas manifestações, os tipos (denúncia, reclamação, solicitação de serviço, sugestão, elogio e crítica) e a determinação do índice de resolubilidade das manifestações, com base no tempo de resposta da Ouvidoria.

Desta forma, destaca-se como objetivo geral dessa pesquisa investigar as demandas e o índice de resolubilidade das manifestações encaminhadas à Secretaria do Trabalho e Desenvolvimento Social (STDS) do Estado do Ceará, em 2015, e, como objetivos específicos, identificar 
o meio de entrada dessas manifestações e os tipos (denúncia, reclamação, solicitação de serviço, sugestão, elogio e crítica) e avaliar o tempo de resposta da Ouvidoria.

Para a realização desse estudo, buscou-se contextualizar as Ouvidorias Públicas no Brasil e em especial no Estado do Ceará, por meio de um estudo bibliográfico; em seguida, foram coletados dados que permitiram destacar o conjunto das manifestações recebidas pela Ouvidoria da STDS no ano de 2015.

\section{DESENVOLVIMENTO}

\subsection{Contexto Histórico das Ouvidorias Públicas no Brasil}

Remontando-se ao período clássico (século V a IV a.C.), na Grécia Antiga, encontram-se os mais remotos registros de controle da administração pública. No entanto, historicamente, a figura do ouvidor ou ombudsman (representante parlamentar, com função de guardião dos interesses do cidadão) teve sua origem na Suécia, por volta de 1809, e, no Brasil, o percurso da instituição das Ouvidorias teve início em 1534, época da colonização portuguesa, quando Tomé de Souza, governador-geral do Brasil, nomeou o primeiro ouvidor-geral do Brasil, Pero Borges, para representar a administração da justiça real portuguesa e atuar como juiz, em nome do rei de Portugal. Com o fim do domínio da coroa portuguesa no Brasil, surgiram diversos movimentos no sentido de implantar a Ouvidoria no Brasil, que, com o golpe de Estado de 1964, foram extintos até o ano de 1986, quando se registra a criação da primeira Ouvidoria Pública brasileira, a Ouvidoria Pública do município de Curitiba (ARAÚJO e MARCELINO, 2010).

Os fundamentos legais e preceitos constitucionais para a elaboração e implementação das Ouvidorias Públicas no Brasil baseiam-se no art. $37^{\circ}$ da Constituição Brasileira, que dispõe sobre os princípios inerentes à Administração Pública, como a legalidade, a impessoalidade, a moralidade, a publicidade e a eficiência, reforçados pela Emenda Constitucional №19, de 1998, que garante a "participação do cidadão na administração pública direta e indireta", regulando especialmente "as reclamações relativas à prestação dos serviços públicos em geral, asseguradas a manutenção de serviços de atendimento ao usuário e a avaliação periódica, externa e interna, da qualidade dos serviços" (BARREIRO, HOSSNE e SOBRINHO, 2011).

A partir do final da década de 1990, ampliaram-se os canais de comunicação entre o Estado e a sociedade, constituindo-se o Ouvidor como o "representante dos cidadãos" no acolhimento das demandas e na atuação da defesa dos direitos do cidadão, com vistas ao aperfeiçoamento da Administração Pública, por meio da transparência e, consequentemente, do processo democrático. Dessa forma, os Estados da federação brasileira passaram a implantar Ouvidorias Públicas, no sentido de garantir o direito dos cidadãos à informação, à qualidade dos serviços públicos prestados pela administração e ao controle social das instituições do Estado.

Ao traçar esse percurso histórico das Ouvidorias Públicas no Brasil, percebe-se um crescimento significativo nesse setor, ocasionando um fortalecimento da governança democrática. É importante destacar que esse crescimento tem provocado uma nova tendência, a criação de redes de Ouvidorias, as quais representam um sistema integrado de gestão que busca assegurar o canal de 
comunicação e representação dos interesses do cidadão diante da Administração Pública, para a resolução ágil das questões apresentadas, promovendo a cidadania e a melhoria da gestão pública.

\subsection{As Ouvidorias Públicas no Estado do Ceará}

Considerando o contexto histórico acima descrito e as transformações pelas quais passou o Estado Brasileiro, aponta-se o Estado do Ceará como a segunda unidade da Federação a instituir - e o fez em 1997 - uma Ouvidoria Estadual. Assim, criou-se nesse ano, a Ouvidoria-Geral do Estado do Ceará. Em 2012 o órgão passou a denominar-se Controladoria e Ouvidoria-Geral do Estado (CGE), estabelecendo-se as funções de Ouvidoria, controladoria, auditoria governamental e correição como essenciais ao funcionamento das atividades de controle da Administração Pública Estadual, dispondo sobre suas finalidades, organização e responsabilidades (Controladoria e Ouvidoria-Geral do Estado do Ceará - CGE).

Dessa forma, a adequação do modelo de funcionamento da CGE em 2013 promoveu a criação do Portal da Transparência do Estado do Ceará, com o objetivo de propiciar ao cidadão um acesso mais simplificado às principais informações do Governo do Estado, permitindo um acompanhamento do montante de recursos públicos arrecadados e como eles estão sendo empregados. De acordo com a CGE, a "Política de Ouvidoria do Estado do Ceará visa a fomentar a participação da sociedade e o exercício do controle social, assegurando o direito à cidadania e à transparência dos serviços prestados pelo Poder Executivo Estadual, com atuação ética, equânime e isenta, por meio da escuta imparcial das partes envolvidas, preservando o direito de livre expressão e julgamento do cidadão". Tal política permitiu a criação da Rede de Ouvidorias do Estado do Ceará, cuja proposta reflete a busca por unicidade e padronização de ações, a criação de metodologias eficientes para a recepção e o tratamento das manifestações, o fortalecimento do diálogo e apoio mútuo e a criação de processos colaborativos, visando à excelência no atendimento ao cidadão.

\subsection{O Papel da Ouvidoria Pública e a Cidadania}

As Ouvidorias Públicas no Brasil, consideradas órgãos do Estado, têm a finalidade precípua de conjugar as expectativas dos indivíduos por serviços públicos e os seus direitos (ROMÃO, 2011), funcionando como uma instância em defesa do cidadão junto à instituição à qual a Ouvidoria representa. Cumprem, portanto, o papel de estabelecer uma comunicação com a população que vise a atender à sua necessidade, buscando exaustivamente a solução do problema enfrentado, buscando a melhoria e correção dos processos da instituição, e sendo capaz de "recomendar e redirecionar o rumo das decisões" (Guia de Ouvidorias Brasil. São Paulo: Padrão Editorial. 2011. p. 15), com a finalidade de atender ao principal interessado: o cidadão.

As Ouvidorias Públicas ampliam a relação da população com a Administração Pública por meio da mediação - método de prevenção consensual de controvérsias -, valendo-se dela e de outras formas de atuação, para assegurar não somente o cumprimento das leis e dos princípios consti- 
tucionais por parte da Administração Pública, mas também dos direitos fundamentais de todos os atores sociais envolvidos. A Ouvidoria representa, segundo BARRETO, HOSSNE e SOBRINHO (2011, p. 65), "um papel social importante no processo dialógico que envolve as relações entre os indivíduos, os grupos e as organizações, desempenhando sua função mediadora, no cotidiano de uma sociedade e de suas instituições".

Destaca-se, no entanto, que as Ouvidorias Públicas, ao funcionarem como instrumento de gestão e participação cidadã na resolução de problemas com os órgãos da Administração Pública, têm como princípio conscientizar o cidadão sobre o direito de seu acesso a um serviço público eficiente, atuando como indutoras no processo de participação e controle social, por meio do diálogo e da disponibilização de informações voltadas para o controle das políticas e ações de governo e, ainda, sua fiscalização e execução.

Para tanto, as Ouvidorias devem promover ações que visem à conscientização da população do direito de cada indivíduo ao acesso à informação e aos serviços públicos de qualidade, assim como também de suas obrigações. Para SALES (2006), a premissa mais significativa de uma Ouvidoria é intermediar e contribuir para a solução de conflitos reais e potenciais, entendendo-se o conflito não na perspectiva negativa, associado às situações ruptura e desintegração, mas sim como um fator importante e necessário para a obtenção de diversas melhorias.

Paralelamente, a institucionalização das Ouvidorias por meio de um conjunto de regras, regimentos e normas, garante a presença legal e contínua da função do Ouvidor enquanto mediador dos interesses individuais e coletivos das instituições, pois elas promovem o diálogo entre as partes envolvidas, possibilitando trazer à luz sugestões e soluções para as questões apontadas. Porém, cabe ressaltar que, entre os profissionais e os especialistas que se dedicam à mediação, não há consenso de que a prática de mediação seja desenvolvida por Ouvidores, em virtude da ausência de leis específicas e de capacitação dos próprios Ouvidores (VOLPI et al., 2011).

Outro aspecto de especial relevância e que deve ser destacado como uma importante característica das Ouvidorias Públicas é a autonomia, pois segundo CAMPOS et al. (2012, p. 32), "a autonomia fortalece seu formato institucional e assegura sua independência em relação aos demais órgãos e entidades da Administração Pública".

Convém ainda destacar que o sucesso na realização de tais funções depende diretamente da capacidade de acolher e oferecer respostas satisfatórias às necessidades do cidadão e de produzir para o Estado informações qualificadas, elaboradas a partir de demandas apontadas pela sociedade, o que implica a necessidade de elo fundamental entre o cidadão, sua demanda e a resposta do Estado. Dessa forma, o exercício da atividade de Ouvidor requer um profissional com conhecimentos, habilidades e atitudes específicas necessárias à atuação nas unidades de Ouvidorias Públicas.

\subsection{O Ouvidor: Agente da Cidadania}

Delineados os conceitos e questões inerentes ao instituto da Ouvidoria Pública e seu papel, cumpre ainda esclarecer o papel do Ouvidor, cuja escolha decorre, preponderantemente, de sua indicação por um superior hierárquico ou da realização de um procedimento eletivo (CAMPOS, 
2012). O Ouvidor será, portanto, a pessoa (profissional do órgão) responsável por receber críticas, reclamações e denúncias de forma imparcial, atuando em favor da administração e do cidadão, fazendo a prevenção, a mediação e a solução de conflitos interpessoais, reais e potenciais, recomendando a suspensão de práticas arbitrárias ou negligentes e impedindo situações de abuso de poder, de forma ética.

Considerando-se, pois, as especificidades do trabalho exercido em uma Ouvidoria Pública, torna-se possível evidenciar na figura do Ouvidor algumas competências que devem compor o perfil profissional desse trabalhador e que podem contribuir para o aperfeiçoamento dos serviços públicos prestados por esses órgãos, tais como a capacidade de mobilizar e articular os conhecimentos, habilidades, atitudes, valores e direitos requeridos nas situações de trabalho e a transparência nos procedimentos administrativos; possuir uma postura sigilosa em relação às informações e aos fatos; ter isenção e agilidade no trato das demandas, além de ter uma conduta ética, ser proativo, autônomo e imparcial, e conhecedor dos serviços prestados pela instituição.

É importante destacar, ainda, a existência de alguns elementos inerentes à personalidade do agente público que assume a função de Ouvidor, cujo perfil deverá evidenciar algumas competências, tais como a capacidade de ouvir e compreender; de reconhecer os cidadãos como sujeitos de direitos; de ter competência para qualificar as expectativas dos cidadãos de forma adequada; de responder aos cidadãos; e de demonstrar os resultados produzidos, desenvolvendo com a equipe atividades de diagnóstico e elaboração de recomendações sobre os serviços prestados ao cidadão, visando à melhoria da qualidade desses serviços, ao aperfeiçoamento da gestão das políticas públicas e ao exercício da participação e controle social sobre a Administração Pública (MARCELINO, 2010). Nesse sentido, O Código de Ética do Ouvidor/Ombudsman indica uma série de princípios éticos e morais que permeiam a atuação do Ouvidor no exercício de suas funções.

No que concerne ao tratamento das demandas recebidas, cabe ao Ouvidor, como representante do cidadão, analisar a manifestação com o objetivo de verificar se a reclamação, denúncia ou sugestão goza de fundamento, a fim de realizar os procedimentos administrativos necessários para dar encaminhamento à manifestação, buscando sempre solucionar ao verificar o problema e corrigi-lo.

Frente ao exposto, é possível determinar que, dentre as competências necessárias ao Ouvidor, as habilidades humanas são fundamentais para o desempenho de suas funções, pois em seu cotidiano são vivenciadas situações de angústia e conflitos. Dessa forma, cabe aos Ouvidores promover a transformação das manifestações de insatisfação do cidadão em ações que estimulem o aperfeiçoamento das políticas públicas prestadas pelo Estado, produzindo informação qualificada que subsidiará decisões estratégicas que melhorarão as ações do Estado, fortalecendo, assim, a democracia.

\subsection{Ouvidorias em Rede: O Sistema de Ouvidorias (SOU) do Governo do Estado do Ceará}

Em um cenário de desafios de ordem econômico-social, política e financeira que permeiam um mundo globalizado e competitivo e as mudanças nos paradigmas das relações entre Estado e 
Sociedade, as Ouvidorias surgem como elemento inovador no processo de formulação e implementação de políticas públicas, tornando-se uma ferramenta de gestão que busca atender às demandas dos cidadãos e agir com eficiência contra as ações de má administração.

As Ouvidorias utilizam, atualmente, diversos canais de comunicação, tais como telefones 0800 , caixas de sugestões/reclamações, e-mails, sites, atendimento presencial etc. Assim, as informações geradas podem subsidiar estudos estratégicos importantes para a Administração Pública, o que impõe a necessidade de uma gestão correta e eficiente dos dados coletados. Dessa forma, a fim de compilar as informações recebidas pelos mais diferentes canais de comunicação que o usuário utiliza, a Ouvidoria necessita contar com um sistema de informação que permita armazenar um banco de informações (dados) de forma segura e confiável, que permita o cruzamento de informações que poderão ser analisadas de forma quantitativa e qualitativa e que forneçam apoio à tomada de decisões e à implementação de novas estratégias organizacionais (POLLONI, 2000, p. 30 apud OLIVEIRA e MARCELINO, 2010).

No caso do Estado do Ceará, a Controladoria e Ouvidoria-Geral do Estado (CGE) instituiu, em 2011, com base no Decreto $n^{\circ} 30.474 / 2011$, um sistema informatizado, denominado Sistema de Ouvidoria (SOU), uma ferramenta informatizada que tem como objetivo otimizar o atendimento das manifestações dos cidadãos, encaminhadas à Ouvidoria, ficando, portanto, todas as etapas do encaminhamento das manifestações registradas. O SOU, após o recebimento das manifestações, deverá proceder à sua apuração, junto à unidade competente, observados os prazos estabelecidos pelo Decreto. Por meio do Sistema, o cidadão pode exercer seus direitos, registrando manifestações de elogios, sugestões, reclamações, solicitações de serviço, críticas e denúncias e acompanhando as providências adotadas e os encaminhamentos. O Sistema faz o acompanhamento da manifestação indicando os prazos de vencimento, a fim de que não seja ultrapassado o prazo limite indicado no Decreto, que determina o prazo máximo de 15 dias para a conclusão da apuração das manifestações no Sistema de Ouvidoria, a contar da data de entrada da manifestação, podendo ser prorrogado pelo dirigente do órgão ou entidade por mais 15 dias, mediante justificativa circunstanciada do Ouvidor setorial.

Constata-se, portanto, que um Sistema de Informação de Ouvidorias é importante em vários aspectos, especialmente em relação à agilidade no tratamento das demandas e controle dos prazos de atendimento, pois, além de facilitar o fluxo das manifestações registradas, permite a padronização dos processos e a geração de relatórios gerenciais qualificados, que servirão de fonte de informações estratégicas para o desenho de ações de governo que visem à melhoria dos serviços prestados aos cidadãos.

Cabe destacar, ainda, que no conjunto das ações relacionadas ao encaminhamento de uma manifestação observa-se a existência de vários subprocessos: recebimento das manifestações; registro; análise e classificação; encaminhamentos; resposta; e arquivamento. Para essa investigação, considerou-se o subprocesso "resposta" como elemento fundamental para a indicação do índice de resolubilidade das manifestações, já que ele reúne os procedimentos que permitem à Ouvidoria oferecer ao cidadão informações sobre seus pleitos, considerando que tal "resposta" deve ser emitida em um prazo de tempo ágil e de forma qualitativamente significativa, o que indicará a resolubilidade da demanda. 
A resolubilidade é um conceito que, a partir da década de 1980, passou a ser amplamente analisado nos estudos da área de saúde, no Brasil, com o objetivo de avaliar os serviços de saúde a partir dos resultados obtidos do atendimento ao usuário. Assim, a principal medida de efetividade é dada pela resolubilidade. Esse conceito tem, portanto, sinonímia com o ato de solucionar e apresenta as seguintes dimensões: a efetividade do serviço; a integralidade; o acesso universal; a satisfação dos usuários; a intersetorialidade; as tecnologias utilizadas pelo serviço; e as demandas e necessidades dos usuários.

Aplicado esse conceito ao desempenho das Ouvidorias Públicas Setoriais do Estado do Ceará, considerar-se-á a resolubilidade como a capacidade de solução da demanda de forma satisfatória, qualitativamente, dentro de um prazo determinado. Assim, a CGE considera, como resolubilidade, as manifestações procedentes respondidas no prazo legal, em até 15 dias, ou entre 16 e 30 dias, com prazo prorrogado, segundo determina o Decreto 30.474/2011. Dito de outra forma, a resolutividade é a solução da demanda do usuário dentro do prazo legal estabelecido. Assim, quanto menor o prazo de solução da demanda, maior será o nível de resolubilidade.

\subsection{Procedimentos Metodológicos}

Tendo como base a fundamentação teórica sobre Ouvidorias Públicas e participação cidadã, e ainda sobre os sistemas informatizados de Ouvidorias, a presente pesquisa propõe-se diagnosticar as demandas e determinar o índice de resolubilidade das manifestações recebidas pela Ouvidoria da Secretaria do Trabalho e Desenvolvimento Social do Estado do Ceará - STDS, no período de 01/01 a 31/12/2015. Considerada, portanto, de cunho bibliográfico, documental, diagnóstica, aplicada e de caráter quantitativo, foi realizada com base nos dados coletados, por meio do Sistema de Ouvidoria (SOU), a fim de identificar o meio de entrada das manifestações, o tipo, o assunto e o tempo de resposta, portanto, estudo de caso.

Foram utilizados como instrumentos de coleta as manifestações (reclamação, denúncia, solicitação de serviço, sugestão, elogio e crítica) registradas no Sistema SOU, no período indicado. Tais manifestações foram registradas no Sistema, por solicitação dos cidadãos cearenses, usuários dos serviços prestados pela Secretaria do Trabalho e Desenvolvimento Social - STDS. Em virtude da manutenção do sigilo dos manifestantes, suas identidades não poderão ser divulgadas.

As manifestações foram analisadas com base nas seguintes categorias: a) Meio de entrada das manifestações: por meio dessa categoria se indicará o meio pelo qual a manifestação foi encaminhada (telefone, internet, 0800, facebook, carta, twitter, governo itinerante, presencial); b) Tipo de manifestação: categoria que indica se a manifestação trata-se de reclamação, denúncia, solicitação de serviço, sugestão, elogio e crítica; c) Assunto: temas das manifestações (serão categorizados os mais recorrentes); d) Assunto e tipo de manifestação (categorização dos assuntos mais recorrentes por tipo de manifestação); e) Tempo de Resposta: determinação do prazo (tempo) de resposta das manifestações.

Os dados quantitativos foram coletados, analisados e encontram-se apresentados em forma de tabelas e gráficos, calculados os dados percentuais referentes aos critérios de análise. Com base 
no resultado do indicador "tempo de resposta", determinou-se o índice de resolubilidade das manifestações. Considerou-se como resolubilidade as manifestações procedentes respondidas no prazo legal, em até 15 dias, ou entre 16 e 30 dias, com prazo prorrogado, segundo determina o Decreto $30.474 / 2011$.

\subsection{Análise dos Resultados}

\subsubsection{Tipo de manifestação}

A Ouvidoria da Secretaria do Trabalho e Desenvolvimento Social (STDS) recebe, por meio do Sistema de Ouvidorias (SOU), um conjunto de manifestações das mais diversas categorias: denúncias, reclamações, solicitações de serviço, sugestões, elogios e críticas. Destacamos na tabela e no gráfico abaixo o conjunto das manifestações recebidas pela Ouvidoria da STDS, no ano de 2015, indicados por quantidade e percentuais:

TABELA 1 - Tipo de Manifestações

\begin{tabular}{|l|l|l|}
\hline TIPO & QUANTIDADE & PERCENTUAL \\
\hline Reclamação & 123 & $38,08 \%$ \\
\hline Denúncia & 110 & $34,06 \%$ \\
\hline Solicitação de Serviço & 52 & $16,10 \%$ \\
\hline Sugestão & 18 & $5,57 \%$ \\
\hline Elogio & 12 & $3,72 \%$ \\
\hline Crítica & 8 & $0,94 \%$ \\
\hline Total & 323 & $100 \%$ \\
\hline
\end{tabular}

FONTE: SOU/CGE/2015

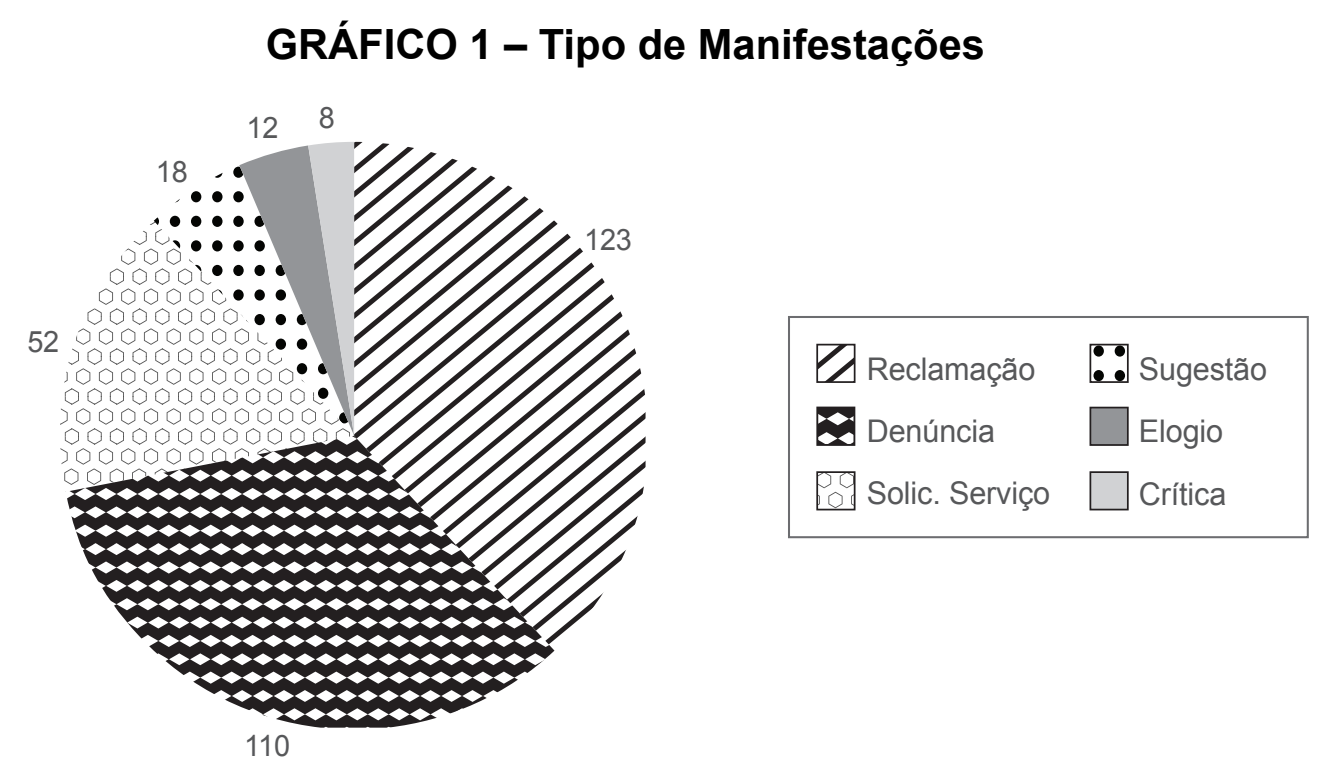

Fonte: SOU/CGE/2015 
Observa-se, conforme destacado no gráfico n¹, que a Ouvidoria da STDS recebeu, em 2015, um conjunto significativo e variado de manifestações, (denúncia, reclamação, solicitação de serviço, sugestão, elogio e crítica), com uma predominância do tipo reclamação e denúncia (percentual de $38 \%$ e $34 \%$, respectivamente), seguido da manifestação do tipo solicitação de serviço, com $16 \%$. É importante observar que as demais manifestações obtiveram registro pouco significativo. Destaque-se que a STDS congrega uma série de equipamentos sociais e projetos institucionais, atuando diretamente na prestação de serviços ao cidadão, o que resulta em uma evidência numérica e percentual dessas duas categorias (reclamação e denúncia) em relação às demais. Consideramos que a prestação direta de serviços à comunidade torna mais visível ao cidadão o trabalho desenvolvido pela instituição e suas entidades conveniadas, ensejando uma maior participação dos usuários.

\subsubsection{Meio de entrada}

As manifestações que ingressam via Sistema SOU podem ser via o próprio Sistema, quando o usuário-cidadão registra via ferramenta SOU sua manifestação, ou ainda pode ser inserida nesse mesmo sistema via operador, quando as manifestações são enviadas por outros meios, como o disk acessibilidade, e-mail, facebook, carta, twiter, governo itinerante ou presencialmente.

Destaca-se, conforme tabela e gráfico $n^{\circ} 2$, o registro das manifestações cadastradas no Sistema de Ouvidoria (SOU) em 2015, relativo ao meio de entrada:

\section{TABELA 2 - Meio de Entrada das Manifestações}

\begin{tabular}{|l|l|l|}
\hline Telefone & 175 & $54,18 \%$ \\
\hline Internet (no sistema SOU) & 136 & $42,11 \%$ \\
\hline (0800) Disk Acessibilidade & 2 & $0,62 \%$ \\
\hline E-mail & 0 & $0 \%$ \\
\hline Facebook & 5 & $1,55 \%$ \\
\hline Carta & 2 & $0,62 \%$ \\
\hline Twiter & 1 & $0,31 \%$ \\
\hline Governo Itinerante & 2 & $0,62 \%$ \\
\hline Presencial & 0 & $0 \%$ \\
\hline TOTAL & 323 & $100 \%$ \\
\hline
\end{tabular}

FONTE: SOU/CGE/2015 


\section{GRÁFICO 2 - Meio de Entrada das Manifestações}
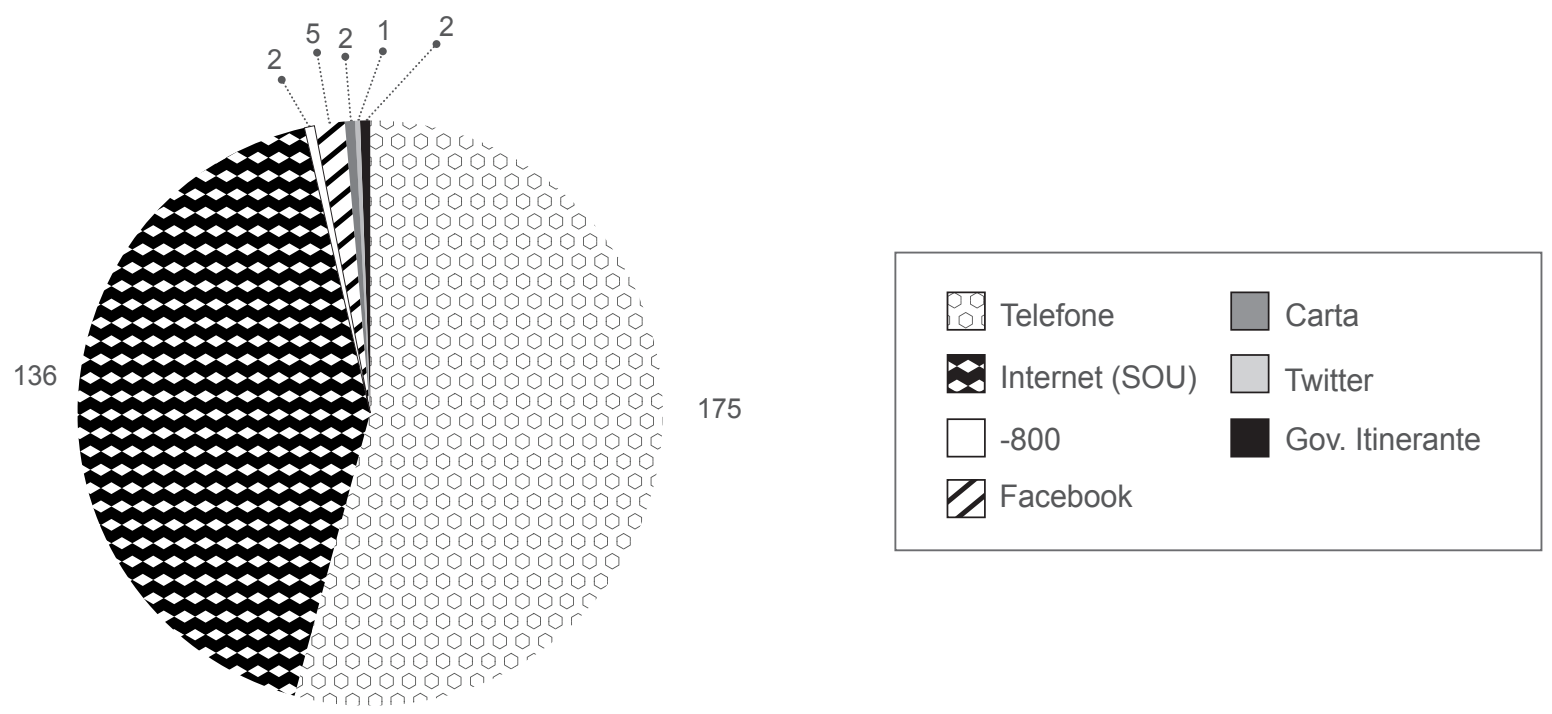

Fonte: SOU/CGE/2015

Percebe-se, segundo o gráfico 2, que os dados evidenciam a ferramenta telefone como principal meio de entrada das manifestações, com índice de $54 \%$, seguido da ferramenta SOU, que registrou índice de $42 \%$. Os demais meios de entrada das manifestações obtiveram índices pouco relevantes. Esses dados revelam que o cidadão utiliza meios mais acessíveis de contato com a Ouvidoria, e consideramos que a evidência da ferramenta telefone justifica-se pela intensa publicidade promovida pela Controladoria e Ouvidoria-Geral do Estado (adesivos em carros oficiais, banners etc.), que divulga o número 155 para realização de denúncias. Também a internet é um meio bastante utilizado, pois a ferramenta SOU permite acesso rápido e fácil ao usuário.

\subsubsection{Assunto}

Em relação ao tópico indicado, considera-se "assunto" o tema geral de que trata o conjunto de manifestações que versam sobre um mesmo argumento. Estão indicados na tabela abaixo os seguintes temas: irregularidades administrativas e funcionais; conduta inadequada do servidor; SINE/ IDT (estrutura e funcionamento); maus tratos a pessoa idosa; atraso/falta de pagamento de pessoal; e outros. No tema "outros" estão inseridos assuntos das mais diversas ordens (estacionamento irregular, limpeza de praças, uso irregular de veículo público, invasões em terrenos públicos, conservação de prédio público etc.), cujas manifestações não representam um conjunto significativo que possa ser classificado sob um mesmo tema. 


\section{TABELA 3 - Assunto das Manifestações}

\begin{tabular}{|l|l|l|}
\hline ASSUNTO & QUANTIDADE & PERCENTUAL \\
\hline $\begin{array}{l}\text { Irregularidades administrativas } \\
\text { e funcionais }\end{array}$ & 38 & $11,76 \%$ \\
\hline Conduta inadequada do servidor & 34 & $10,53 \%$ \\
\hline $\begin{array}{l}\text { SINE/IDT (estrutura e } \\
\text { funcionamento) }\end{array}$ & 23 & $7,12 \%$ \\
\hline Maus tratos a pessoa idosa & 10 & $3,10 \%$ \\
\hline $\begin{array}{l}\text { Atraso / falta de pagamento } \\
\text { de pessoal }\end{array}$ & 11 & $3,41 \%$ \\
\hline Outros & 207 & $64,9 \%$ \\
\hline Total & 323 & $100 \%$ \\
\hline
\end{tabular}

FONTE: SOU/CGE/2015

GRÁFICO 3 - Assunto das Manifestações

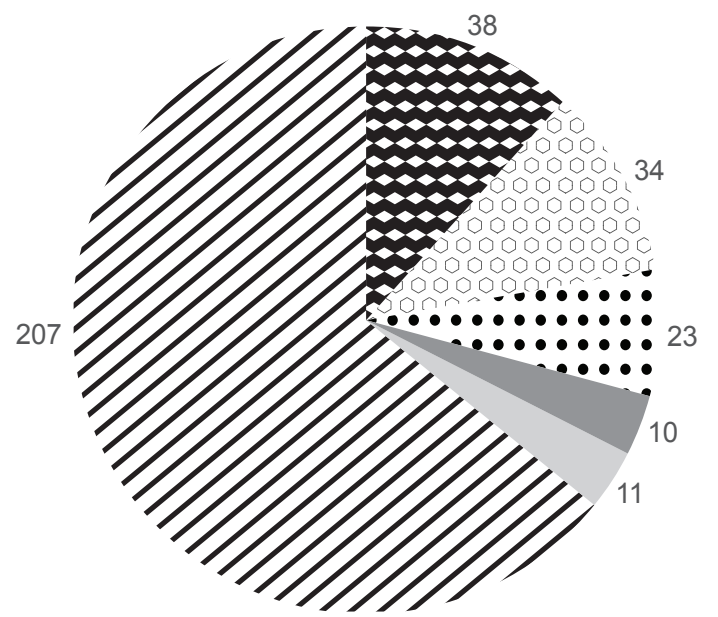

Irreg. Adm. e Funcionais
$\square$ Cond. Inadequada Servidor
$\square$ Atraso/pagamento
$\square$ SINE/IDT

Fonte: SOU/CGE/2015

Apresentados no gráfico $\mathrm{n}^{\circ} 3$, destaca-se com um percentual de $64,9 \%$ o tema "outros", cuja categoria reúne manifestações de diversas temáticas, que não representam um conjunto de manifestações que versam sobre um mesmo tema. Observa-se com isso a descentralização das temáticas que revelam a participação cidadã em vários assuntos que incluem desde a falta de manutenção de um prédio público até o estacionamento irregular de veículo da instituição. Dessa forma, merecem 
destaque os índices referentes às manifestações catalogadas sob um mesmo tema, como, por exemplo, "irregularidades administrativas" com um índice de $11,76 \%$, seguida de "conduta inadequada do servidor" com índice de 10,53\% e "estrutura e funcionamento das unidades do SINE/IDT" com $7,12 \%$, já que revelam a reiteração de uma reclamação e ou denúncias, exigindo da Ouvidoria especial atenção, dada a recorrência de alguns fatos.

Ainda sobre o tipo de manifestação, apresentam-se na tabela 3 dados referentes aos assuntos dos diferentes tipos de manifestação que ingressaram via sistema, no ano de 2015.

\section{TABELA 4 - Assunto por Tipo de Manifestação}

\begin{tabular}{|c|c|c|c|}
\hline $\begin{array}{l}\text { TIPO DE } \\
\text { MANIFESTAÇÃO }\end{array}$ & ASSUNTOS DAS MANIFESTAÇÕES & & TOTAL \\
\hline \multirow{4}{*}{ Reclamação } & Irregularidades administrativas e funcionais & 16 & \multirow{4}{*}{123} \\
\hline & Conduta inadequada de servidor & 15 & \\
\hline & Insatisfação com o atendimento prestado no órgão/entidade & 14 & \\
\hline & Outros & 78 & \\
\hline \multirow{4}{*}{ Denúncia } & Irregularidades administrativas e funcionais & 22 & \multirow{4}{*}{110} \\
\hline & Conduta inadequada de servidor & 18 & \\
\hline & Centro Educacional Patativa do Assaré - Internação & 12 & \\
\hline & Outros & 58 & \\
\hline \multirow{4}{*}{ Elogio } & Elogio à Ouvidoria & 3 & \multirow{4}{*}{12} \\
\hline & Elogio aos serviços prestados pelo órgão & 2 & \\
\hline & Elogio a servidor público/colaborador & 2 & \\
\hline & Outros & 5 & \\
\hline \multirow{4}{*}{ Sugestão } & Programa de assistência social & 4 & \multirow{4}{*}{18} \\
\hline & Estrutura e funcionamento de equipamentos/órgãos públicos & 3 & \\
\hline & Programas e projetos de assistência social & 2 & \\
\hline & Outros & 9 & \\
\hline \multirow{4}{*}{$\begin{array}{l}\text { Solicitações de } \\
\text { Serviços }\end{array}$} & Programas e projetos de assistência social & 4 & \multirow{4}{*}{52} \\
\hline & Sine IDT (Estrutura e Funcionamento) & 4 & \\
\hline & Programa de assistência social & 3 & \\
\hline & Outros & 41 & \\
\hline \multirow{4}{*}{ Críticas } & Conduta inadequada de servidor & 1 & \multirow{4}{*}{8} \\
\hline & Consocial (Conferencia Estadual) & 1 & \\
\hline & Insatisfação com a resposta da instituição & 1 & \\
\hline & Outros & 5 & \\
\hline Total Geral & & & 323 \\
\hline
\end{tabular}

FONTE: SOU/CGE/2015

130 | Revista Científica da Associação Brasileira de Ouvidores/Ombudsman - Ano 1 - nº 1 - 2017/2018 
Como podemos observar na tabela acima, dependendo do tipo de manifestação (reclamação, denúncia, elogio, sugestão, solicitação de serviço e crítica), nota-se uma recorrência em relação a determinados "assuntos", como, por exemplo, "irregularidades administrativas", que aparece nas manifestações do tipo reclamação e denúncia, e o assunto "conduta inadequada do servidor", que aparece nas manifestações do tipo reclamação, denúncia e crítica.

\subsubsection{Tempo de resposta}

Na categoria "tempo de resposta", inserem-se todas as manifestações recebidas pela STDS no ano de 2015 (323 manifestações), com a indicação do tempo de resposta de cada uma delas: no prazo; fora do prazo; e invalidadas. Dessa forma, entende-se que a manifestação foi respondida no prazo, se a resposta foi enviada respeitando o prazo limite de 15 dias para resposta à demanda, com prorrogação para 30 dias, de acordo com o Decreto 30.474/2011. Entende-se por invalidada a manifestação cujo texto não explicita de forma clara o tipo de denúncia ou reclamação da qual é objeto. Na maioria das vezes o texto é vago, sem informações que permitam a identificação do problema.

\section{TABELA 5 - Tempo de Resposta}

\begin{tabular}{|l|l|l|}
\hline & QUANTIDADE & PERCENTUAL \\
\hline No prazo & 312 & $96,59 \%$ \\
\hline Fora do prazo & 8 & $2,48 \%$ \\
\hline Invalidadas & 6 & $0,93 \%$ \\
\hline Total & 323 & $100 \%$ \\
\hline
\end{tabular}

FONTE: SOU/CGE/2015

\section{GRÁFICO 5 - Tempo de Resposta}

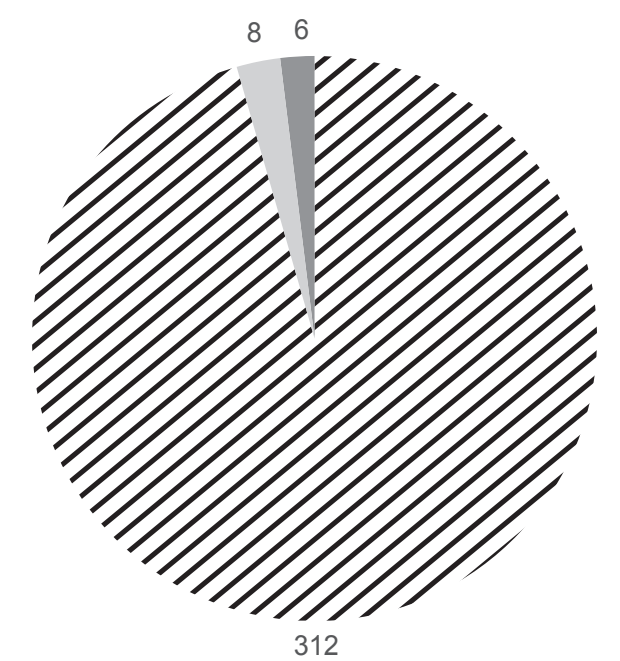


Considerando os dados acima indicados podemos depreender que a grande maioria das manifestações (96\%) foi respondida dentro do prazo estabelecido pelo Decreto 30.474/2011, ou seja, foi obedecido o período de 15 dias indicados e apenas 2,48\% das manifestações foram respondidas fora do prazo determinado. Com base nesse diagnóstico, e considerando que a resolubilidade, no caso da Ouvidoria Pública, atende exclusivamente a critérios de respeito ao prazo estabelecido no Decreto para o encaminhamento de uma resposta satisfatória ao cidadão, apontamos um índice de resolubilidade de $96 \%$ no conjunto das manifestações recebidas pela Ouvidoria da STDS no ano de 2015.

\section{CONSIDERAÇÕES FINAIS}

As Ouvidorias Públicas no Brasil exercem um papel importante na construção da cidadania e constituem um relevante instrumento de transformação das instituições, na medida em que contribuem para a melhoria e o aprimoramento dos serviços por elas prestados.

Este trabalho abrangeu um breve histórico sobre o instituto das Ouvidorias Públicas no Brasil e no Estado do Ceará, abordando questões relativas aos conceitos de Ouvidoria, participação cidadã e o papel do Ouvidor, além de discorrer sobre o Sistema de Ouvidorias do Estado do Ceará, ferramenta utilizada para apuração e resposta das manifestações dos cidadãos.

Com base no estudo realizado, verificou-se que a utilização de um sistema de Ouvidorias em rede, além de tornar mais eficaz a comunicação entre o cidadão usuário e o Estado, possibilita a padronização dos procedimentos, a geração de informações precisas e confiáveis, cujos dados servem de instrumento de análise do desempenho das Ouvidorias setoriais.

Os dados percentuais obtidos nesta pesquisa demonstram que, no período de janeiro a dezembro de 2015, a Ouvidoria da Secretaria do Trabalho e Desenvolvimento Social (STDS) recebeu um quantitativo bastante considerável de manifestações (323) dos mais diversos tipos (denúncia, reclamação, solicitação de serviço, sugestão, elogio e crítica) e assuntos (irregularidades administrativas e funcionais, conduta inadequada do servidor, SINE/IDT - estrutura e funcionamento -, maus tratos a pessoa idosa e atraso/falta de pagamento de pessoal), sendo que a maior concentração delas foi do tipo "reclamação" (123 ou 38,8\%), o que evidencia a insatisfação do cidadão com a prestação de serviços.

Verifica-se que, do conjunto de 323 (trezentas e vinte e três) manifestações encaminhadas, a Ouvidoria da STDS respondeu 312 (trezentas e doze) manifestações dentro do prazo determinado pelo Decreto $30.474 / 2011$, o que nos permitiu calcular um índice de resolubilidade de $96 \%$. Esse índice revela a capacidade da Ouvidoria em garantir um feedback com rapidez e eficiência às manifestações recebidas e o uso de técnicas de gestão adequadas ao cumprimento de seus objetivos, contribuindo para a satisfação do usuário.

Considera-se que este estudo de caso contribuirá para as pesquisas relativas aos papéis desempenhados pelas Ouvidorias Públicas no Brasil, especialmente aqueles relacionados à participação direta do cidadão e ao uso de sistemas de informações de Ouvidorias, e seus resultados servirão como indicadores para aperfeiçoar o tratamento das manifestações recebidas pela Ouvidoria da 
STDS, gerando impactos na rotina de trabalho e melhoria de indicadores. Além disso, como consequência, a Ouvidoria poderá aperfeiçoar a prestação de serviço, identificar os eventuais gargalos e ampliar a participação deste instrumento de gestão e de participação cidadã.

Com base nos dados coletados, conclui-se que a Ouvidoria da STDS apresentou um índice bastante satisfatório de resolubilidade das manifestações, ou seja, quase todas as manifestações foram respondidas de forma satisfatória, no prazo de 15 dias, salientando seu nível de eficiência. No entanto, cabe destacar que os resultados apresentados no mapeamento detalhado dessas manifestações revelam, ainda, a necessidade de priorizar e orientar ações de melhoria em algumas áreas de atuação da STDS, em especial as dos serviços prestados à sociedade.

\section{REFERÊNCIAS}

ARAÚJO, Charlanne K.; MARCELINO, Karla J. A. Importância da Ouvidoria para a Secretaria de Recursos Hídricos e Energéticos. Revista Científica da Rede de Ouvidorias do Estado de Pernambuco. Recife: Ouvidoria-Geral do Estado, 2010

BACELLAR, Roberto Portugal. Juizados Especiais: a nova mediação paraprocessual. São Paulo: Revista dos Tribunais, 2003.

BRASIL. Constituição da República Federativa do Brasil de 1988. Brasília: Presidência da República, Casa Civil, 2013. Disponível em: <http://www.planalto.gov.br>. Acesso em: 06 abr. 2016.

BARREIRO, A.; HOSSNE, D.; SOBRINHO, F. Ética e Ouvidoria Pública. In: Construindo a Ouvidoria no Brasil. Campinas, SP: Unicamp/Ouvidoria, 2011. p. 59-76.

CARDOSO, Antônio Semeraro Rito. Ouvidorias Públicas como Instrumento de Mudança. In: LYRA, Rubens Pinto (Org.); CARDOSO, Antônio Semeraro Rito (Org.). Novas modalidades de Ouvidoria Pública no Brasil. João Pessoa: Editora Universitária da UFPB, 2011.

CAMPOS, Adriana (Coord.) et al. Por um Sistema Nacional de Ouvidorias Públicas: possibilidades e obstáculos. Série Pensando o Direito, v. 42. Brasília: Ministério da Justiça, Secretaria de Assuntos Legislativos, 2012.

CARVALHO NETO, A. Contrato de Mediação. São Paulo: Jalovi, 1991.

CONTROLADORIA E OUVIDORIA-GERAL DO ESTADO DO CEARÁ - CGE. Disponível em: www.cge.ce.gov.br. Acesso em: 05 jul. 2016.

GUIA DE OUVIDORIAS BRASIL: ASSOCIAÇÃO BRASILEIRA DE OUVIDORES - ABO, São Paulo, 2011. Disponível em: http://www.abosaopaulo.org.br/artigo.php?codigo=18. Acesso em: 10 jun. 2016

CEARÁ. Decreto 30.474, de 29 de março de 2011. Institui o Sistema de Ouvidoria-SOU e dá outras providências. Disponível em: www.cge.ce.gov.br/index.php/regulamentomenu/.../356-apresentacao-do-novo-sou. Acesso em: 11 jun. 2016.

LYRA, Rubens Pinto. Ouvidor: o defensor dos direitos na Administração Pública brasileira. In: Autônomas x obedientes: a Ouvidoria Pública em debate. p.119-152. João Pessoa: Ed. UFPB, 2004

(Org. e Coautor). Modalidades de Ouvidoria Pública no Brasil. João Pessoa: Ed. UFPB, 2009. $\overline{U F P B}, 2010$.

Ouvidorias e Ministério Público: as duas faces do Ombudsman no Brasil. João Pessoa: Editora Universitária

MARCELINO, Karla J. A Gestão por Competências - Resultados da pesquisa de satisfação da Rede de Ouvidorias de Pernambuco. Revista Científica da Rede de Ouvidorias do Estado de Pernambuco. Recife, 2010, p. 41-56.

REVISTA CIENTÍFICA DA REDE DE OUVIDORIAS DO ESTADO DE PERNAMBUCO. Recife, Ouvidoria-Geral do Estado, 2010. 
PEREZ, J. Roberto; BARREIRO, Adriana Eugênia A.; PASSONE, Eric (Org.). Construindo a Ouvidoria no Brasil: Avanços e perspectivas. Campinas, SP: Unicamp, 2011

OLIVEIRA, Izabela Mendes; Marcelino, Karla Júlia. A contribuição da tecnologia de informação e comunicação para as Ouvidorias Públicas. Revista Científica da Rede de Ouvidorias do Estado de Pernambuco. Recife, 2010, p. 41-56.

Revista Científica da Rede de Ouvidorias do Estado do Pernambuco. Recife, Ouvidoria-Geral do Estado, 2010.

ROMANO, R. Ética e Ouvidoria. Curso de Capacitação e Certificação de Ouvidores. São Paulo: Associação Brasileira de Ouvidores/Ombudsman, 2008.

ROMÃO, José Eduardo Elias. O papel das Ouvidorias Públicas na efetivação do controle social. VII Fórum Brasileiro de Controle da Administração Pública: Direito Fundamental ao Bom Governo. Rio de Janeiro, 2011.

SALES, L.M.M. Ouvidoria e mediação: instrumentos de acesso à cidadania. Pensar, Fortaleza, v. 11, p. 154-167, 2006.

VISMONA, E. L. A Ouvidoria no Brasil. São Paulo: Imprensa Oficial, 2000.

VOLPI et. al. Mediação e Ouvidoria. In: Construindo a Ouvidoria no Brasil, op.cit., 2011. p. 77-104. 